William Poole is the president and CEO of the Federal Reserve Bank in St. Louis. This article is a slightly edited version of a speech of the same title he presented before The St. Louis Gateway Chapter of the National Association for Business Economics, St. Louis, Missouri, September 16, 1998. The views expressed are those of the author and do not necessarily reflect those of other Federal Reserve officials.

\section{A Policymaker Confronts Uncertainty}

William Poole

\section{The St Louis Gateway Chapter National Association for Business Economics St. Louis, Missouri}

\section{September 16, 1998}

W hen, in August, I chose a title for these remarks I thought my approach would be academic in tone. Little did I guess that the topic would be immediate and obvious because of the press of events, both abroad and at home. Uncertainties abound in today's environment. I must say, though, that the uncertainties we face have been in the background all along. What is different at the moment, and worth remembering, is that the uncertainties are simply very obvious right now.

I have long been interested in the analysis of monetary policy under uncertainty. The problems arise from what we do not know; we must deal with the uncertainty from the base of what we do know. The general public seems to have a vastly unrealistic view of how much the Fed knows, and sometimes assumes that the problem is simply that the issues are so complicated that only the experts can understand them. In fact, the basic issues of uncertainty can be explained quite readily.

I will, shortly, talk more precisely about the current policy situation facing the Fed, but before getting into current issues, I do want to indulge my academic proclivities by providing an outline of the sources of uncertainty we face.

\section{SOURCES OF UNCERTAINTY}

I divide the sources of uncertainty facing the monetary policymaker into five categories: 1) the data; 2) future events, shocks and disturbances; 3 ) how the economy works; 4) market reactions to Fed policy; and 5) market anticipations of Fed policy. Let me talk briefly about each of these and then turn to a policy framework for dealing with uncertainties.

\section{Data}

Economics is an empirical science, and the lifeblood of every empirical science is the data necessary to confirm theoretical propositions and to establish the regularities upon which scientific inference depends. U.S. data are pretty good, but we are constantly finding gaps and questionable areas in our base of empirical knowledge. Day in and day out we struggle to interpret the flow of current information and must al ways be al ert to various possible anomalies and biases. Let me provide just one example that has been of interest in recent quarters.

M easuring wage inflation is of tremendous importance in trying to understand whether unexpectedly robust growth in nominal demand is feeding through not only to lower unemployment but also to higher than desired increases in wages. For tracking wages, I rely heavily on the Employment Cost Index (ECI), for that index is constructed to provide the best possible measure of increases in labor compensation. A key feature of the index is that it tracks compensation changes occupation by occupation, position by position, and is meant to be free of distortions that arise from changes in the industry composition of employment and the percentage of overtime in total employment. The question 
that analysts must deal with now is whether wage inflation may be taking the form of promotions to higher grades in firms' employment ladders. That type of wage inflation would not show up in the $\mathrm{ECl}$, which tracks changes in compensation grade by grade.

\section{Future Events}

The course of the economy will obviously depend on things that happen in the future. Because of the lags in the effects of policy changes, I want the Fed to act ahead of future events that would require policy adjustments. Yet, my crystal ball is little better than anyone else's. The private market did not foresee the severity of developments in Asia, nor did I. Obviously, every forecaster does the very best he can at forecasting the future, but, without question, the difference between what actually happens and the forecast can be very large indeed.

\section{How the Economy Works}

The interplay of developments in economic theory and empirical observation has enormously improved our understanding of the macro economy over the last 50 years. Yet, there are extremely important areas subject to wide dispute. A key area today, and much in the news, is the magnitude of the wealth effect on household spending. The recent decline in the stock market may depress consumption spending substantially, or maybe it won't. In recent years, consumption spending has been high relative to the current flow of disposable income. It is certainly consistent with the hypothesis of a substantial wealth effect to observe this low saving rate out of current income. Households have been relying on the appreciation in the stock market to increase wealth, and have, therefore, felt comfortable in spending a large fraction of current disposable income. Under this argument, the decline in the stock market should indeed be expected to reduce consumption. How- ever, the effects may come about with a long lag, and there are other possible hypotheses to explain the high level of consumption in recent years. The fact of the matter is that I really am not confident about the size of the wealth effect.

\section{Market Reactions to Fed Policy}

The economy's response to a Fed policy adjustment will depend importantly on whether the market believes the policy adjustment is temporary, permanent, or the first of a series of policy adjustments in the same direction. I want to separate this discussion from the immediate policy situation, so let's think back to a year ago (before I arrived at the St. Louis Fed). At that time, the economy was growing robustly, and there were possible signs of overheating. Suppose that last fall the Fed had raised the federal funds rate by 25 basis points. The economy's response would presumably have been minimal if the market anticipated that the Fed was going to bring the funds rate back to $5 \frac{1}{2}$ percent in a matter of a few months. Or, the economy's response would be somewhat greater if the market believed that the 25 basis point increase was likely to remain in effect for, say, a year. The effect on the economy would have been even larger if the market viewed the funds rate as the first of a series of increases.

Everyone, both inside the Fed and out, is well aware of this argument. But at the time the Fed is considering a policy change, I have little insight into how the market will actually react to a policy change of 25 basis points in the funds rate. To some extent, the Fed can shape this reaction by what it says, but I am not myself confident that I can predict the reaction.

Moreover, uncertainty about how the market will react is by no means the end of the matter. If a Fed policy adjustment takes the market largely by surprise as was the case with the increase in the funds rate in February 1994, the market reaction may be one of wholesale revision of expectations about the state of the economy. If the market believes the inflation environment is benign, for example, and the Fed 
tightens policy, the market may then suddenly develop a case of inflation jitters simply because it believes that the Fed has a case of inflation jitters. (Of course, the Fed never has "jitters" only "concerns.") Still, this problem of making the market's judgments coincide with the Fed's judgments is an extremely difficult part of the policy problem the Fed faces. One of the biggest risks we face is a gap between the market's expectation of Fed policy and what the Fed actually does.

\section{Market Anticipations of Fed Policy}

Closely related to the problem of uncertainty over market reactions to Fed policy is the uncertainty of market anticipations of Fed policy. The difficulty here is that the Fed should not adjust policy simply because the market expects it. That said, mistaken decisions in private markets may arise if Federal Reserve policy does not match the anticipated policy.

\section{DEALING WITH \\ UNCERTAINTY}

So, what do we do? At the outset, we need to be clear about several things. First of all, at any given time the Fed receives an ample amount of advice from every direction and, therefore, after the fact someone or other will al ways have had things pegged better than the Fed did. But that is not the right criterion for judging the wisdom of policy decisions. We must make the judgments on the basis of ex ante considerationsyou pay your money and make your bets before the game is played. The issue is al ways whether the Fed is making a mistake that is predictable at the time the decision is being made. With all of the uncertainties in the environment, it is rarely the case that the Fed make obvious ex ante mistakes. Or at least so it seems to me in recent years.

Second, we should al ways keep in mind that the Federal Reserve has essentially only one policy instrument. I like to think of that instrument as the amount of money the Fed creates, but for those who prefer to con- centrate on the federal funds rate, the issue is exactly the same. However you put it, the Fed controls just one policy instrumentmoney growth or the funds rate.

With one policy instrument, the Fed can achieve at best one policy goal. My conviction, which I believe is the overwhelming view in the economics profession, is that the goal must be the rate of inflation. If the Federal Reserve is successful in keeping the rate of inflation low and stable if, roughly speaking, the economy enjoys sustained price stability, then the Fed will have done its job and done it well. Price stability aids the efficiency of the economy and from recent evidence it also appears to be hel pful in holding down the average level of unemployment. But with one policy instrument, the Fed cannot aim directly at economic growth, the unemployment rate, the level of the stock and bond markets, the exchange rate, the growth of the Japanese economy, and so forth and so on. To use a simple analogy, when driving a car we need a steering wheel to control direction, an accelerator and brake to control speed, and a transmission to control forward or reverse. If the only control instrument available were the steering wheel, at best we could control direction. There would be no use in al so trying to control speed.

This point, which is so obvious to professional economists, is extremely important in the current environment. Many are calling on the Fed to reduce interest rates to $\mathrm{calm}$ the market. Some argue that cutting rates in the United States will promote a more healthy financial and growth environment abroad, will ease the pressing financial problems in Russia, and so forth and so on. The fact of the matter is that with one policy instrument the Federal Reserve cannot do all of these things. An attempt to pursue other objectives that in fact damaged pursuit of price stability in the United States would only add to world financial problems. The most important contribution theF ederal Reservecan make is to maintain price stability at home, and the economic stability that accompanies achievement of that goal. Do not misinterpret me; improving growth prospects in Japan and 
elsewhere around the world is an important objective. It is just that, in my judgment, the Federal Reserve does not have policy instruments to further this objective. Of course, if financial turmoil in the world threatens to depress the U.S. economy, then adjustment of U.S. monetary policy is appropriate, and I have no doubt that the Fed will make that adjustment when the case for it is clear.

A second important policy principle for dealing with uncertainty is that we need to minimize errors in the market's expectation of what the Federal Reserve is going to do. These errors can never altogether be eliminated, because what the Federal Reserve will do depends in good measure on events that no one can forecast. But what the Fed can do is to reiterate its conviction that maintaining price stability is the primary, indeed almost exclusive in my view goal of monetary policy. I believe that the market in recent years has in fact come to interpret the Fed's actions and analyses within that context. The Federal Reserve should also share its views with the markets and explain the reasons for its policy decisions. This is not by any means an easy job, because individual FOMC members may differ on the rationale for a given policy change. That is, it is typically the case that FOMC members can agree on what to do without being able to agree with great precision on exactly why the action is appropriate. Different economists, quite naturally, have different views on what the most compelling circumstances are in any given situation.

Another important principle is that we should rely on built-in market stabilizers to the maximum possible extent. Let me provide a very brief background on this important topic, which is by no means fully explored or understood at the level of the professional journal literature. Chicago-school economists have long argued that a steady rate of money growth would set a firm basis for the market to form expectations about the long-run course of monetary policy. Given confidence in price stability, markets could then respond to current information and current economic conditions by adjusting interest rates to equilibrate saving and investment at full employment. This vision of monetary policy did not ultimately prevail, most likely because of the disturbances caused by unpredictable changes in money demand in the short run. Still, the principle of relying on market mechanisms to equilibrate markets to the maximum possible extent still holds.

Under the Fed's operating procedure of fixing the federal funds rate in a narrow range in the short run, it appears that a built-in stabilizing mechanism, a mechanism not anticipated in the policy debates of the 1960s and 1970s, does operate. The market moves longer-term interest rates by substantial amounts given the base of the federal funds rate and given market confidence in continued low inflation. The federal funds rate has been constant at $5 \frac{1}{2}$ percent from $M$ arch of last year to the time of this writing. Over this period, long-term interest rates fluctuated very substantially. The way the process seems to be working is that the market has increasingly become convinced of the Federal Reserve's objective of maintaining price stability and has been adjusting longer-term interest rates on the basis of those firm low-inflation expectations. As market rates fluctuate, the incentives for businesses and households to spend on capital goods and consumer durables rise and fall. Of course, this process can only work if the Federal Reserve does in fact adjust the funds rate in due time, as required by emerging economic conditions. And that, I believe, is exactly what the Federal Reserve has done to the best of its ability.

If I am correct with this analysis, then the market should have confidence that the Federal Reserve will adjust the federal funds rate up or down as required by emerging developments to keep the economy at low inflation. There does seem to be a substantial amount of room to time these adjustments so as to further the objective of stability in growth and employment. But the key to this process is that the market must believe that the Fed's long-term goal is (after al lowing for the biases in broad price indexes) true price stability - neither inflation nor deflation.

In setting interest rates, the market should al ways concentrate on the funda- 
mentals of the situation, rather than on trying to guess what the Federal Reserve is going to do next. The Fed is concentrating on the fundamentals; if the market is correct in judging that the fundamentals will require an interest rate adjustment, then as the data arrive and future prospects change the Federal Reserve will indeed change interest rates in the anticipated direction. However, under current circumstances, the Federal Reserve does have the luxury of waiting to be sure that the fundamentals do indeed point in a particular direction. That luxury is an extremely important gain from the Fed's investment in policy credibility. Because the market trusts the Fed to keep inflation low and stable, we do not have large changes in inflation expectations complicating our policy decisions.

\section{THE POLICY ENVIRONMENT TODAY}

Applying these comments to today's circumstances, it is obvious to everyone who watches the markets that the level of interest rates has declined in anticipation of a Fed easing of the federal funds rate sometime within the next few months or few quarters. I can be quite vague about the timing because the timing doesn't really matter very much to a holder of a 30-year bond. If the fundamentals do come in as the market anticipates, and let me reiterate the importance of that conditional word "if," then of course the Fed will act. However, the possible future events are by no means one-sided. If the situation were perfectly clear, the Federal Reserve would al ready have adjusted rates.

I am, I hope, only saying very obvious things, but it is extremely important that we be clear about these obvious things to avoid misinterpretation of the Fed's policy and what I am saying about it. If it turns out that the economy remains much more buoyant than the market seems to anticipate at this time, and especially if it turns out that we see inflationary pressures rising, then the next adjustment in interest rates could be up, rather than down. Most of the adjustment would be in market rates, as new information changes market perceptions about the likely course of events. In time, the Fed might want to move the funds rate up under these circumstances, but analysts should not underestimate the importance of the built-in stabilizing effects from market adjustments of interest rates.

My discussion so far has been about what I call the first great principle of monetary policy - the pursuit day in and day out of price stability in an environment inherently riddled with uncertainties.

Let me finish with a brief word about the second great principle of monetary policy: the need for the Federal Reserve to act under extraordinary circumstances to provide extra liquidity to the marketplace. Every now and then, a crisis erupts in which the market mechanism itself breaks down. These are rare occurrences, as evidenced by the list of events in recent years that have required extraordinary liquidity provision. (The most famous recent case is the stock market crash of 1987, during which the market mechanism for trading equities was under extraordinary stress as evidenced by trading volume outrunning the capacity of the marketplace, the panic conditions, and the concerns over the viability of several securities firms.) In this circumstance, the Fed acted vigorously to provide extra funds to the market until conditions quieted and the panic subsided. Another circumstance was the near failure of Continental Illinois Bank in 1984, during which the market mechanism for large-bank CDs was severely strained and spreads widened as investors developed great uncertainties about the entire CD market. The Fed intervened to smooth over that market upset. Another case was the Penn Central Railroad bankruptcy in 1970. In this case, the market for commercial paper was disrupted.

These infrequent events require prompt and vigorous Federal Reserve actions to provide extra liquidity and reassurance to the market. The essential feature of these periods is not only that market prices are moving, but also that the market mechanism itself is breaking down in some way. Remember once again that the Federal 
Reserve has only one policy instrument. We cannot simultaneously achieve our goal of price stability and provide support to each individual market in the economy. The Fed's day-in and day-out policy must be concerned with price stability. As a nation we rely on many different mechanisms for keeping the economy humming along smoothly and efficiently. We rely on private markets with decisions made by millions of individual participants to solve problems in the distribution of goods and in the determination of securities prices. We rely on the mechanisms of government spending and taxes and regulation to solve many other allocation and distribution problems in our economy. The Federal Reserve's role is a key one, but it is just part of the society's mechanism for producing good outcomes for the long run.

\section{SUMMARY}

I'll finish with a very brief summary of my analysis. The Fed faces many uncertainties, and must adjust its one policy instrument to navigate as best it can this sea of uncertainty. The fundamental principle is that the Fed should use that one policy instrument to achieve long-run price stability. The Fed, by making clear to everyone its commitment to that goal, is able to rely increasingly on market adjustments of interest rates to equilibrate the economy. The Fed needs to adjust the funds rate target from time to time, but not day in and day out.

The second great principle of monetary policy is that the Fed should stand ready to provide extra liquidity to stabilize markets in those rare circumstances that panic is breaking down the market mechanism itself. Because U.S. markets work so well, extraordinary policy intervention is fortunately extraordinarily rare.

My bottom line is that market participants should concentrate on the fundamentals, and so should the Fed. With success in maintaining price stability, the Fed will need to adjust its policy instrument from time to time, but if the bond traders can get it right they'll do much of the stabiliza- tion work. We at the Fed can then sit back and enjoy life. 